\title{
Clinical Pharmacology Research in India: A Scientometric Assessment of Publication Output during 2005-14
}

\author{
K K Mueen Ahmed', B. M. Gupta ${ }^{2}$ and Ritu Gupta ${ }^{3}$ \\ ${ }^{1}$ Phcog.Net and SciBiolMed.Org, Bengaluru, Karnataka, INDIA. \\ ${ }^{2}$ Formely CSIR-NISTADS, New Delhi (Present Address: 1173 Sector 15, Panchkula 134 113, Haryana, INDIA. \\ ${ }^{3}$ Department of Library \& Information Science, Sri Venkateswara University, Tirupathi-517502, Andhra Pradesh \\ (Present Mailing Address: 1KA Arjun Nagar, Safdarjang Enclave, New Delhi 11029), INDIA.
}

\begin{abstract}
The paper examines 8519 publications on clinical pharmacology research in India as covered in Scopus database during 2005-14, using various quantitative and qualitative parameters with a focus on its growth, citation quality, share of national international collaborative papers, subject-wise distribution, contribution and contribution and impact of its leading scholars, contribution to most productive journals, etc.India's global publication share in clinical pharmacology was 4.80 , which increased from $2.65 \%$ to $6.69 \%$ from 2005-09 to 2010-14. India's publications in clinical pharmacology witness an annual average growth rate of $25.89 \%$ and citation per paper of 6.75 during 2005-14, which decreased from 9.14 to 4.08 from 2005-09 to $2010-14$. Nearly $61 \%$ of the Indian publications onclinical pharmacology registered citations from 0 to 605 citations and these citations witnessed highly skewed distribution. India's share of international collaborative publications in the total output was $12.22 \%$ during $2005-14$, which decreased from $13.99 \%$ to $11.76 \%$ from $2005-09$ to $2010-14$. The top 15 most productive Indian organizations and authors together contributed $19.25 \%$ and $4.71 \%$ and $29.06 \%$ and $8.39 \%$ share of the cumulative publications and
\end{abstract}

citations output of India in clinical pharmacology during 2005-14. The 10 most productive journals in India's clinical pharmacology research together contributed $33.82 \%$ share to the total India's publication output in clinical pharmacology during 2005-14. India's publication output in clinical pharmacology had on 51 highly cited papers (receiving 100 or more citations) and together received 8597 citations, leading to average citation per paper of 168.57.

Correspondence :

Ritu Gupta,

Department of Library \& Information Science, Sri Venkateswara University, Tirupathi-517502, Andhra Pradesh, (Present Mailing Address: 1K/A Arjun Nagar, Safdarjang Enclave, New Delhi 11029), INDIA.

Phone no: 9722563995

E-mail: bmgupta1@gmail.com

DOI: 10.5530/jyp.2016.4.4

\section{INTRODUCTION}

Clinical pharmacology is defined as the science of drugs and their clinical use, with added focus on the application of pharmacological principles and quantitative methods. Its scope varies from the discovery of new target molecules to the effects of drug usage in populations and connects the gap between medical practice and laboratory science. Its main objective is to promote the safety of prescription, maximize the drug effects and minimize the side effects. It is important that there be association with pharmacists skilled in areas of drug information, medication safety and other aspects of pharmacy practice related to clinical pharmacology. Clinical pharmacologists evaluate the evidence and produce new data through well designed studies. Clinical pharmacologists must have access to enough outpatients for clinical care, teaching and education, and research as well is supervised by medical specialists. Their responsibilities to patients include, but are not limited to analyzing adverse drug effects, therapeutics, and toxicology including reproductive toxicology, cardiovascular risks, peri-operative drug management and psychopharmacology. In addition, the application of genetic, biochemical, or viro-therapeutical techniques has led to a clear appreciation of the mechanisms involved in drug action. The various branches of clinical pharmacology include: (i) Pharmacodynamics - finding out what drugs do to the body and how, including not just the cellular and molecular aspects, but also more relevant clinical measurements; (ii) Pharmacokinetics - what happens to the drug while in the body, involving the body systems for handling the drug, usually divided into the following classification:Absorption, Distribution, Metabolism and Excretion; (iii) Rational Prescribing - using the right medication, at the right dose, using the right route and frequency of administration for the patient, and stopping the drug appropriately; (iv) Adverse Drug Effects, (v) Toxicology, (vi) Drug interactions and (vii) Drug development - usually culminating in some form of clinical trial. ${ }^{1}$

Clinical pharmacologists focus is on developing and understanding new drug therapies and they work in a variety of settings in academia, industry and government: (i) In the laboratory setting, they study biomarkers, pharmacokinetics, drug metabolism and genetics, (ii) In the office setting, they design and evaluate clinical trials, create and implement regulation guidelines for drug use, and look at drug utilization on local and global scales and (iii) In the clinical setting, they work directly with patients, participate in experimental studies, and investigate adverse reactions and interactions. ${ }^{2}$

Clinical pharmacology was developed as a discipline in the 1960s in USA, Europe, and UK. ${ }^{3-5}$ At the same time, clinical pharmacology began in India due to efforts of stalwarts like Dr. U.K. Sheth, Dr. Ranjit Roy chaudhary, Dr. P. L. Sharma, and many others. ${ }^{6}$ In the past 50 years or more, the discipline has grown very fast. However, now there is an enormous need of trained clinical pharmacologists. The pharmaceutical industry has prospered. There is generic pharmaceutical industry, which is multibillion dollar in business in India. ${ }^{7}$ With changes in patent laws and drug regulations, large numbers of clinical trials are being done in developing countries, on drugs developed in other countries as well as on new drugs developed by local industry and academia. ${ }^{8}$ On the other hand, in the public health scenario, there are several government and even industry initiatives to expand the coverage of healthcare and reach medicines to rural areas. ${ }^{9}$ To meet industry needs, there has been a great rush to develop clinical trials sites, contract research organizations, and bioavailability centers. But, there is need to provide training in clinical pharmacology and clinical research to contribute to public health, hospital practice, and ethical drug development process. 
Indian Council of Medical Research (ICMR), Department of Health Research (DHR), Department of Biotechnology (DBT) and AYUSH (Ayurveda, Unani, Siddha, and Homeopathy) Departments of the Government of India have initiated programs in specialized areas. The Indian Council of Medical Research has been conducting workshops on clinical pharmacology for nearly 40 years at Seth G. S. Medical College and King Edward Memorial (KEM) Hospital, Mumbai. ${ }^{4}$

The part time and short-term existing certificate courses on clinical research in India are not accredited, are classroom-based, and provide little practical training in healthcare settings, in industry or at regulatory agencies. The contents of the programs are not updated, and there is very little faculty development or updates. Most training programs in clinical research train students in implementing clinical trial protocols. While this is important, investigator-driven studies intended to answer relevant questions are vital in the context of advancing knowledge, bridging gaps, developing guidelines and policies, as emphasized in a recent editorial in the Lancet. ${ }^{10}$ Postgraduate courses offered by universities, such as the Ph.D., M.D. Pharmacology, D.M. Clinical Pharmacology, Ph.D. Clinical Pharmacy, M.Sc. Pharmaceutical Medicine, and Ph.D. Pharmaceutical Medicine, train students in hypothesis generation, framing research questions, and designing appropriate studies. The M.D., M.S., D.M., and M.Ch. courses in other clinical disciplines also do train students in clinical research. However, they give importance to learning clinical skills for patient care. The number of M.D., M.S., D.M., and M.Ch. places is grossly inadequate for societal needs for patient care, and very few students are able to devote time to research. ${ }^{11}$

\section{Literature Review}

There were no bibliometric and scientometric study so far on the measurement of research activities in clinical pharmacology both at nation$\mathrm{al}$ and international level. However few studies have been carried out on quantitative analysis of pharmacology research in India. Among such studies, Mueen Ahmed, Gupta and Gupta ${ }^{12}$ analyzed the performance of Indian pharmacological research during 2003-12, based on several parameters including global publication share and rank of 15 most productive countries, India's publication growth rate and citations impact, its pattern of citations output, international collaboration profile, institutional profile, geographical distribution of output, contribution and impact of top institutions and authors, pattern of communications and characteristics of high cited papers. Gupta, Mueen Ahmed and Gupta ${ }^{13}$ analyzed high productivity organizations in pharmaceutical science in India during 2008-12 and identified their overall strength measured in terms of select quantitative and qualitative indicators. It also provided a comparative evaluation and performance of different types of Indian pharmaceutical organizations. Nayak, Mor and Unnikrishnan ${ }^{14}$ analyzed research output (1947 to the end of 2009) from Indian pharmacy schools consisting of 10680 publications with a total of 45010 citations. The annual rate of increase in publications peaked at 30 to $40 \%$ between 2005 and 2007. Karnataka came first with more than $16 \%$ of the country's publications and over $13 \%$ of citations. The top ten schools bagged about 52\% publications and $70 \%$ citations. Dr Harisingh Gour University, Sagar was found to have published the maximum number of publications and Panjab University for the highest citations as well as citations per paper.

\section{OBJECTIVES}

The main objectives of this study are to study the performance of Indian research in clinical pharmacology research during 2005-14, based on publications covered in Scopus database. In particular, the study focuses on the following objectives: (i) To study the growth of world and Indian research output and the citation impact of the Indian research; (ii) To study the global publication share of top 15 most productive countries and the place of India in global output; (iii) To study the international collaboration share and the contribution of leading foreign countries in India's collaborative output; (iv) To identify significant keywords; (v) To study the publication productivity and citation impact of 15 most productive organizations and authors; (vii) To study the medium of communication and characteristics of high cited papers.

\section{METHODOLOGY}

The study retrieved and downloaded the publication data of the world and of 15 most productive countries in clinical pharmacology from the Scopus database (http://www.scopus.com) for 10 years during 2005-14. The data on clinical pharmacology in India was downloaded using the following three search strategies. In the first search strategy publication data on Indian pharmacological output was searched using "India" in Affiliation Country tag and then limit to subject area "Pharmacology" and limit to period "2005-2014". In the second search strategy all publications on clinical research was searched in India using keyword "Clinical" in "Article, Title, Abstract, Keywords" tag and "India" in Affiliation Country tag and limit to time period "2005-14". In the final and third search strategy the above two search strategy was combined to get publication output on clinical pharmacology in India. The $3^{\text {rd }}$ search became our main search string. When the main search string with restricted to 15 most productive countries in "country tag", as shown below, the publication data on 15 productive countries were obtained. When the main search string is further restricted to "subject area tag", "country tag", "source title tag", "journal title name" and "affiliation tag", we got information on distribution of publications by subject, collaborating countries and organization-wise, etc. For citation data, citations to publications were also collected from date of publication till the end of October 2015. AFFILCOUNTRY(India) AND PUBYEAR > 2004 AND PUBYEAR < 2015 AND ( LIMIT-TO(SUBJAREA,"PHAR")).

(TITLE-ABS-KEY(clinical) AND AFFILCOUNTRY(India))

AND PUBYEAR $>2004$ AND PUBYEAR $<2015$.

((AFFILCOUNTRY(India) AND PUBYEAR > 2004 AND PUBYEAR < 2015) and ((TITLE-ABS-KEY(clinical) AND AFFILCOUNTRY(India)) AND PUBYEAR > 2004 AND PUBYEAR < 2015)) AND ( LIMITTO(SUBJAREA,"PHAR")).

\section{Analysis}

The world and India has published 177465 and 8519 publications on clinical pharmacology during 2005-14, which increased from 15680 and 284 publications in 2005 to 20332 and 1565 publications in 2014, registering an annual average growth rates of $3.01 \%$ and $25.89 \%$. The cumulative growth of world and Indian publications in clinical pharmacology increased from 83004 and 22023 during 2005-09 to 94421 and 6317 publications during 2010-14, witnessing a growth rate of $13.70 \%$ and $186.88 \%$. India's global publications share in clinical pharmacology was $4.80 \%$ during 2005-14, which increased from 2.65\% during 2005-09 to $6.69 \%$ during $2010-14$. The average citation per publication registered by Indian publications in clinical pharmacology was 6.75 during 200514 , which decreased from 14.38 during 2005-09 to 4.08 during 201014 (Table 1). Of the 8519 publications in clinical pharmacology during $2005-14,75.43 \%$ (6426) appeared as articles, $18.86 \%$ (1607) as reviews, $2.86 \%(244)$ as letters, and the rest less than $1 \%$ : editorials $(0.80 \%)$, conference papers $(0.70 \%)$, short surveys $(0.65 \%)$, notes $(0.41 \%)$, book chapters and articles in press $(0.13 \%$ each $)$ and erratum $(0.02 \%)$. 


\section{Citation Distribution of Papers}

Only $60.89 \%$ of the Indian publications (3332) onclinical pharmacology were cited, receiving 100 to 605 citations since their publication till October 2015. Citation distribution of Indian clinical pharmacology publications (5187) was highly skewed: Nearly $44.59 \%$ (3799) publications accounted for 1 to 10 citations per paper (23.277\% citation share). Around $58.59 \%$ (4991) publications accounted for 11 to 50 citations per paper (68.97\% citation share). And $1.73 \%$ (147) publications accounted for 51 to 100 citations ( $17.14 \%$ citation share). The remaining $0.58 \%$ (49) publications accounted for more than 7978 citations (13.88\% citation share) (Table 2).

\section{International Collaboration}

The share of international collaborative publications in India's clinical pharmacology research output was $12.22 \%$ during 2005-14, which decreased from $13.99 \%$ during 2005-09 to $11.76 \%$ during 2010-14 (Table 1). India has collaborated with several countries in clinical pharmacology research during 2005-14. Among the collaborating countries, the largest share $(43.52 \%)$ was contributed by United States, followed by UK (12.10\%), Australia (6.44\%), Canada (6.24\%), Malaysia (6.15\%), Saudi Arabia (5.96\%), Belgium (5.86\%), Germany (5.67\%), Switzerland (5.48\%) and South Korea (5.84\%) during 2005-14. The international collaborative publications share of foreign countries in India's publications output increased by $5.59 \%$ in Saudi Arabia, followed by Malaysia (4.94\%), Belgium (3.62\%), South Korea (3.55\%), Australia (3.05\%) and Switzerland $(0.78 \%)$, as against decrease by $6.08 \%$ in USA, followed by U.K. (3.25\%), Canada (2.27\%) and Germany (1.24\%) from 2005-09 to 2010-14 (Table 3).

\section{Global Publication Share \& Citation Impact of Top 15 Most Productive Countries}

The global research output in clinical pharmacology originated in more than 100 countries during 2005-14. Table 2 lists the output of top 10 most productive countries in clinical pharmacology during 2005-14. The publication share of 10 most productive countries in clinical pharmacology varied from $3.64 \%$ to $32.70 \%$ during $2005-14$, with highest publication share $(32.70 \%)$ coming from USA, followed by U.K. (8.74\% share), China (7.37\%), Germany (6.28\%), Italy (5.79\%), Japan (4.82\%), India (4.04\%), Spain (3.88\%), France (3.70\%) and Canada (3.64\%) during 2005-14. The global publication share has increased by $5.07 \%$ in China, followed by India $(4.04 \%)$, Italy $(0.15 \%)$ and France $(0.12 \%)$, as against decrease by $1.44 \%$ by USA, Germany (0.97\%), U.K. (0.78\%), Canada (0.59\%), Spain $(0.45 \%)$ and Japan $(0.17 \%)$ from 2005-09 to 2010-14 (Table 4).

\section{Significant Keywords}

Around 70 significant keywords have identified in clinical pharmacology research literature, which throw light on the nature of research undertaken in Indian organizations in this area. These significant keywords are listed in Table 5 along with their frequency of occurrence (5).

\section{Profile of Top 15 Most Productive Organizations}

The productivity of 15 most productive Indian organizations in clinical pharmacology varied from 66 to 235 publications and together contributed $19.25 \%$ (1640 publications)and 29.06\% (16696) share of the cumulative publications and citations output of India in clinical pharmacology during 2005-14. The scientometric profile of these 15 Indian organizations is presented in Table 6 . Four organizations have registered higher publications output than the group average of 109.33:All India Institute of Medical Sciences (AIIMS), New Delhi (235 papers), Postgraduate Institute of Medical Education \& Research (PGIMER), Chandigarh and Jamia
Hamdard University, Delhi (163 papers each) and National Institute of Pharmaceutical Education \& Research (NIPER), Mohali (119 papers) during 2005-14.

Six organizations have registered more than the average citation per publication (10.18) among the 15 organizations during 2004-15: Dr Hari Singh Gaur University, Sagar (19.31), National Institute of Pharmaceutical Education \& Research (NIPER), Mohali (16.33), Jamia Hamdard University, Delhi (13.58), Central Drug Research Institute (CDRI), Lucknow (13.49), Panjab University, Chandigarh (13.04) and Jadavpur University, Kolkata (11.1) during 2005-14.Eight organizations have registered more than the average h-index (16.8) of all 15 organizations: Dr Hari Singh Gaur University, Sagar and Jamia Hamdard University, Delhi (25 each), National Institute of Pharmaceutical Education \& Research (NIPER), Mohali and Panjab University, Chandigarh (22 each), Central Drug Research Institute (CDRI), Lucknow (21), Postgraduate Institute of Medical Education \& Research (PGIMER), Chandigarh (20), All India Institute of Medical Sciences (AIIMS), New Delhi (19) and Jadavpur University, Kolkata (17) during 2005-14.

Seven organizations have achieved more than the average share of international collaborative publications $(11.13 \%)$ of all organizations: Christian Medical College (CMC), Vellore (26.44\%), Institute of Medical Sciences, Banaras Hindu University (BHU-IMS), Varanasi (25.29\%), C.S.Maharaj Medical University, Lucknow (17.39\%), National Institute of Pharmaceutical Education \& Research (NIPER), Mohali (16.81\%), All India Institute of Medical Sciences (AIIMS), New Delhi (13.19\%), Jadavpur University, Kolkata (12.99\%) and Jamia Hamdard University, Delhi (12.27\%) during 2005-14.

\section{Profile of Top 15 Most Productive Authors}

The productivity of 15 most productive Indian authors in clinical pharmacology varied from 19 to 40 publications and together contributed $4.71 \%$ (401 publications) and $8.39 \%$ (4823) share in the cumulative publications and citations output of India in clinical pharmacology in India during 2005-14. The scientometric profile of these 15 Indian authors is presented in Table 7. Seven authors have registered higher publications output than the group average of 26.73: R. Srinivas (40 papers), T. Monif and S. Sundar (37 papers each), R. Mullangi (35 papers), P. Pandhi and S.P. Vyas (29 papers each) and S. Malhotra (27 papers) during 2005-14. Six authors have registered more than the average citation per publication (12.03) among all 15 authors: R.K. Khar (32.37), M. Aqil (26.43), S. Sundar (20.11), F.J. Ahmad (19.00), K. Chopra (17.64) and S.P.Vyas (16.34) during 2005-14. Six authors have registered more than the average h-index (9.47) of all 15 authors during 2005-14:S. Sundar (16), S.P. Vyas (14), R.K. Khar and K. Chopra (13), F.J. Ahmad and R. Mullangi (11 each) during 2005-14. Three authors have achieved more than the average share of national collaborative publications $(15.71 \%)$ of all authors: S. Sundar (72.97\%), T. Monif (48.65\%) and F.J. Ahmad (15.79\%) during 2005-14.

\section{Medium of Communication}

The 10 most productive journals in India's clinical pharmacology research contributed 125 to 614 papers and together contributed $33.82 \%$ share (2881 papers) to the total India's publication output in clinical pharmacology during 2005-14. The publication share of these top 15 most productive journals increased from $24.80 \%$ to $36.96 \%$ from $2005-09$ to 2010-14. The most productive journal (with 614 papers) was Journal of Anesthesiology, followed by Research Journal of Pharmaceutical, Biological \& Chemical Sciences (427 papers), International Journal of Pharmacy \& Pharmaceutical Sciences (342 papers), Asian Journal of Pharmaceutical \& Clinical Research (321 papers), etc during 2005-14 (Table 8). 
Ahmed et al.: Clinical Pharmacology Publications Output

Table 1: Growth of World and India's Research in Clinical Pharmacology, 2005-14

\begin{tabular}{ccccccc}
\hline \multirow{2}{*}{$\begin{array}{c}\text { Publication } \\
\text { Year }\end{array}$} & Global & \multicolumn{5}{c}{ India } \\
\cline { 2 - 7 } 2005 & TP & TP & TC & CPP & ICP & $\%$ ICP \\
\hline 2006 & 15680 & 284 & 5035 & 17.73 & 46 & 16.20 \\
2007 & 15964 & 365 & 6439 & 17.64 & 62 & 16.99 \\
2008 & 17058 & 397 & 6477 & 16.31 & 45 & 11.34 \\
2009 & 16525 & 668 & 7642 & 11.44 & 80 & 15.37 \\
2010 & 17328 & 857 & 8496 & 9.91 & 97 & 11.32 \\
2011 & 18063 & 1163 & 6883 & 5.92 & 136 & 11.69 \\
2012 & 19119 & 1312 & 5462 & 4.16 & 153 & 11.66 \\
2013 & 19579 & 1420 & 3523 & 2.48 & 165 & 11.62 \\
2014 & 20332 & 1565 & 1438 & 0.92 & 192 & 12.27 \\
$2005-09$ & 83044 & 2202 & 31659 & 14.38 & 308 & 13.99 \\
$2010-14$ & 94421 & 6317 & 25802 & 4.08 & 743 & 11.76 \\
$2005-14$ & 177465 & 8519 & 57461 & 6.75 & 1041 & 12.22 \\
\hline
\end{tabular}

$\mathrm{TP}=$ Total Papers; $\mathrm{TC}=$ Total Citations; $\mathrm{CPP}=$ Citations Per Paper; $\mathrm{ICP}=$ International Collaborative Papers.

Table 2: Citation Distribution of Indian Publications on Clinical Pharmacology, 2005-14

\begin{tabular}{ccccc}
\hline Citation Range & No. of Papers & No. of Citations & Share of Papers & Share of Citations \\
\hline 0 & 3332 & 0 & 39.11 & 0.00 \\
$1-10$ & 3799 & 13374 & 44.59 & 23.27 \\
$11-20$ & 683 & 10132 & 8.02 & 17.63 \\
$21-30$ & 279 & 6986 & 3.28 & 12.16 \\
$31-40$ & 154 & 5484 & 1.81 & 9.54 \\
$41-50$ & 76 & 3660 & 0.89 & 6.37 \\
$51-100$ & 147 & 9847 & 1.73 & 17.14 \\
$<100$ & 49 & 7978 & 0.58 & 13.88 \\
& 8519 & 57461 & 100.00 & 100.00 \\
\hline
\end{tabular}

Table 3: Share of Leading Countries in India's International Collaborative Output in Clinical Pharmacology during 2005-14

\begin{tabular}{ccccccc}
\hline $\begin{array}{c}\text { Name of } \\
\text { Collaborative } \\
\text { Country }\end{array}$ & \multicolumn{2}{c}{ No. of Collaborative Papers } & \multicolumn{3}{c}{ Share of Collaborative Papers } \\
\cline { 2 - 7 } & $\mathbf{2 0 0 5 - 0 9}$ & $\mathbf{2 0 1 0 - 1 4}$ & $\mathbf{2 0 0 5 - 1 4}$ & $\mathbf{2 0 0 5 - 0 9}$ & $\mathbf{2 0 1 0 - 1 4}$ & $\mathbf{2 0 0 5 - 1 4}$ \\
\hline USA & 146 & 307 & 453 & 47.40 & 41.32 & 43.52 \\
U.K. & 44 & 82 & 126 & 14.29 & 11.04 & 12.10 \\
Australia & 13 & 54 & 67 & 4.22 & 7.27 & 6.44 \\
Canada & 24 & 41 & 65 & 7.79 & 5.52 & 6.24 \\
Malaysia & 8 & 56 & 64 & 2.60 & 7.54 & 6.15 \\
Saudi Arabia & 6 & 56 & 62 & 1.95 & 7.54 & 5.96 \\
Belgium & 10 & 51 & 61 & 3.25 & 6.86 & 5.86 \\
Germany & 20 & 39 & 59 & 6.49 & 5.25 & 5.67 \\
Switzerland & 15 & 42 & 57 & 4.87 & 5.65 & 5.48 \\
South Korea & 4 & 36 & 40 & 1.30 & 4.85 & 3.84 \\
Total of India & 308 & 743 & 1041 & 100.00 & 100.00 & 100.00 \\
\hline
\end{tabular}


Table 4: Publication Output and Global Publication Share of Top 10 Most Productive Countries in Clinical Pharmacology, 2005-14

\begin{tabular}{ccccccc}
\hline \multirow{2}{*}{$\begin{array}{c}\text { Name of the } \\
\text { Country }\end{array}$} & \multicolumn{3}{c}{ Number of Papers } & \multicolumn{3}{c}{ Share of Papers } \\
\cline { 2 - 7 } & $2005-09$ & $2010-14$ & $2005-14$ & $2005-09$ & $2010-14$ & $2005-14$ \\
\hline USA & 27790 & 30237 & 58027 & 33.46 & 32.02 & 32.70 \\
U.K. & 7605 & 7913 & 15518 & 9.16 & 8.38 & 8.74 \\
China & 3881 & 9197 & 13078 & 4.67 & 9.74 & 7.37 \\
Germany & 5642 & 5496 & 11138 & 6.79 & 5.82 & 6.28 \\
Italy & 4739 & 5529 & 10268 & 5.71 & 5.86 & 5.79 \\
Japan & 4082 & 4479 & 8561 & 4.92 & 4.74 & 4.82 \\
India & 2202 & 6317 & 8519 & 2.65 & 6.69 & 4.80 \\
Spain & 3422 & 3469 & 6891 & 4.12 & 3.67 & 3.88 \\
France & 3016 & 3545 & 6561 & 3.63 & 3.75 & 3.70 \\
Canada & 3278 & 3174 & 6452 & 3.95 & 3.36 & 3.64 \\
World & 83044 & 94421 & 177465 & 100.00 & 100.00 & 100.00 \\
\hline
\end{tabular}

Table 5: Frequency Distribution of Significant Keywords in Clinical Pharmacology Literature during 2005-14

\begin{tabular}{|c|c|c|c|c|c|c|c|}
\hline Keyword & Freq. & S.No & Keyword & Freq. & S.No & Keyword & Freq \\
\hline Drug efficacy & 1493 & 25 & Drug stability & 258 & & Abdominal pain & 113 \\
\hline Drug safety & 996 & 26 & Apoptosis & 256 & 49 & Anti viral activity & 105 \\
\hline Drug effect & 617 & 27 & Apoptosis & 256 & 50 & Anti diabetic activity & 103 \\
\hline Drug mechanism & 582 & 28 & Staphylococcus aureus & 241 & 51 & Anemia & 100 \\
\hline Drug structure & 554 & 29 & Drug potency & 243 & 52 & Prostate cancer & 94 \\
\hline Drug formulation & 479 & 30 & Medicinal plants & 239 & 53 & Ovary cancer & 77 \\
\hline Plant extract & 467 & 31 & Drug metabolism & 238 & 54 & Lung cancer & 74 \\
\hline Diabetes mellitus & 449 & 32 & Drug release & 231 & 55 & Gastrointestinal disease & 73 \\
\hline Drug bioavailability & 448 & 33 & Antimicrobial activity & 228 & 56 & Colorectal cancer & 72 \\
\hline Hypertension & 448 & 34 & Cardiovascular disease & 224 & 57 & Colon cancer & 67 \\
\hline Drug screening & 437 & 35 & Drug delivery systems & 221 & 58 & Ischemic disease & 65 \\
\hline Drug synthesis & 421 & 36 & Breast cancer & 219 & 59 & Heart disease & 63 \\
\hline Drug tolerability & 408 & 37 & Drug solubility & 218 & 60 & Heart arrhythmia & 62 \\
\hline Drug half life & 401 & 38 & Drug design & 216 & 61 & Anti malarial activity & 59 \\
\hline Anti bacterial activity & 383 & 39 & Drug determination & 216 & 62 & Lung no small cell cancer & 58 \\
\hline Non insulin dependent diabetes mellitus & 373 & 40 & Anti fungal activity & 208 & 63 & Coronary artery disease & 58 \\
\hline Anti oxidant activity & 366 & 41 & Rheumatic arthritis & 145 & 64 & Congestive heart failure & 53 \\
\hline Diarrhea & 360 & 42 & Depression & 143 & 65 & Melanoma & 53 \\
\hline Anti neoplastic activity & 356 & 43 & Asthma & 141 & 66 & Pancreas cancer & 50 \\
\hline Enzyme activity & 351 & 44 & Anti algestic activity & 134 & 67 & Head \& neck cancer & 42 \\
\hline Headache & 305 & 45 & Alzheimer disease & 130 & 68 & Hear muscle ischemia & 41 \\
\hline Anti inflammatory activity & 305 & 46 & Obesity & 126 & 69 & AIDS & 19 \\
\hline Drug absorption & 297 & 47 & Diabetes mellitus Type 2 & 115 & & & \\
\hline Neoplasm & 280 & 48 & Cardio vascular risk & 113 & & & \\
\hline
\end{tabular}


Table 6: Scientometric Profile of Top 15 Most Productive Indian Organizations in Clinical Pharmacology, 2005-14

\begin{tabular}{|c|c|c|c|c|c|c|}
\hline Name of the Organization & TP & TC & ACPP & $\mathrm{HI}$ & ICP & $\% \mathrm{ICP}$ \\
\hline All India Institute of Medical Sciences (AIIMS), New Delhi & 235 & 1708 & 7.27 & 19 & 31 & 13.19 \\
\hline Postgraduate Institute of Medical Education \& Research (PGIMER), Chandigarh & 163 & 1360 & 8.34 & 20 & 13 & 7.98 \\
\hline Jamia Hamdard University, Delhi & 163 & 2214 & 13.58 & 25 & 20 & 12.27 \\
\hline National Institute of Pharmaceutical Education \& Research (NIPER), Mohali & 119 & 1943 & 16.33 & 22 & 20 & 16.81 \\
\hline Central Drug Research Institute (CDRI), Lucknow & 104 & 1403 & 13.49 & 21 & 8 & 7.69 \\
\hline Panjab University, Chandigarh & 121 & 1578 & 13.04 & 22 & 6 & 4.96 \\
\hline Annamalai University & 102 & 795 & 7.79 & 13 & 11 & 10.78 \\
\hline Dr Hari Singh Gaur University, Sagar & 89 & 1719 & 19.31 & 25 & 10 & 11.24 \\
\hline Christian Medical College (CMC), Vellore & 87 & 774 & 8.90 & 14 & 23 & 26.44 \\
\hline Institute of Medical Sciences, Banaras Hindu University (BHU-IMS), Varanasi & 87 & 858 & 9.86 & 16 & 22 & 25.29 \\
\hline Jawaharlal Institute of Postgraduate Medical \& Research (JIPMER), Pondicherry & 80 & 597 & 7.46 & 12 & 5 & 6.25 \\
\hline Kasturba Medical College (KMC), Manipal & 78 & 226 & 2.90 & 7 & 6 & 7.69 \\
\hline Jadavpur University, Kolkata & 77 & 855 & 11.10 & 17 & 10 & 12.99 \\
\hline C.S.Maharaj Medical University,Lucknow & 69 & 468 & 6.78 & 12 & 12 & 17.39 \\
\hline Vellore Institute of Technology & 66 & 198 & 3.00 & 7 & 2 & 3.03 \\
\hline Total of 15 organizations & 1640 & 16696 & 10.18 & 252 & 199 & 12.13 \\
\hline Total of India & 8519 & 57461 & & & & \\
\hline Share of 15 organizations in India's total output & 19.25 & 29.06 & & & & \\
\hline
\end{tabular}

Table 7: Scientometric Profile of Top 15 Most Productive Indian Authors in Clinical Pharmacology during 2005-14

\begin{tabular}{cccccccc}
\hline Name of Author & Affiliation of Author & TP & TC & ACPP & HI & ICP & \%ICP \\
\hline R. Srinivas & Dr Reddy Laboratories (DRL), Gurgaon & 40 & 300 & 7.50 & 9 & 1 & 2.50 \\
T. Monif & DRL, Gurgaon & 37 & 115 & 3.11 & 5 & 18 & 48.65 \\
S. Sundar & BHU-IMS, Varanasi & 37 & 744 & 20.11 & 16 & 27 & 72.97 \\
R. Mullangi & DRL, Gurgaon & 35 & 350 & 10.00 & 11 & 2 & 5.71 \\
P. Pandhi & PGIMER, Chandigarh & 29 & 259 & 8.93 & 9 & 1 & 3.45 \\
S.P. Vyas & Dr H.S.Gaur Univ., Sagar & 29 & 474 & 16.34 & 14 & 4 & 13.79 \\
S. Malhotra & PGIMER, Chandigarh & 27 & 248 & 9.19 & 9 & 1 & 3.70 \\
K.K. Pillai & Jamia Hamdard Univ., Delhi & 25 & 126 & 5.04 & 7 & 2 & 8.00 \\
K. Chopra & Panjab Univ., Chandigarh & 22 & 388 & 17.64 & 13 & 0 & 0.00 \\
T.K. Pal & Jadavpur University, Kolkata & 22 & 110 & 5.00 & 6 & 0 & 0.00 \\
M. Aqil & Jamia Hamdard Univ., Delhi & 21 & 555 & 26.43 & 9 & 1 & 4.76 \\
P.A. Patil & J.N.Medical College, Belgium & 20 & 20 & 1.00 & 2 & 0 & 0.00 \\
R.K. Khar & Jamia Hamdard Univ., Delhi & 19 & 615 & 32.37 & 13 & 1 & 5.26 \\
F.J. Ahmad & Jamia Hamdard Univ., Delhi & 19 & 361 & 19.00 & 11 & 3 & 15.79 \\
Kumar & Panjab Univ., Chandigarh & 19 & 158 & 8.32 & 8 & 2 & 10.53 \\
& Total of 15 authors & 401 & 4823 & 12.03 & 9.47 & 63 & 15.71 \\
\hline & Total of India & 8519 & 57461 & & & & \\
\hline
\end{tabular}


Ahmed et al.: Clinical Pharmacology Publications Output

\begin{tabular}{cccc} 
Table 8: List of Most Productive Journals in Clinical Pharmacology Research in India during 2005-14 \\
\hline Name of the Journal & \multicolumn{3}{c}{ Number of Papers } \\
\cline { 2 - 4 } Journal of Anesthesiology & $2005-09$ & $2010-14$ & $2005-14$ \\
\hline Sciences & 309 & 305 & 614 \\
Research Journal of Pharmaceutical, Biological \& Chemical & 0 & 427 & 427 \\
International Journal of Pharmacy \& Pharmaceutical Sciences & 3 & 339 & 342 \\
Asian Journal of Pharmaceutical \& Clinical Research & 9 & 312 & 321 \\
Indian Journal of Pharmacology & 98 & 200 & 298 \\
Indian Journal of Pharmaceutical Science. Review \& Research & 0 & 208 & 208 \\
Indian Journal of Physiology \& Pharmacology & 96 & 112 & 208 \\
International Journal of Research in Ayurveda\& Pharmacy & 0 & 179 & 179 \\
Indian Journal of Forensic Medicine \& Toxicology & 31 & 128 & 159 \\
Journal of Pharmacy \& Biomedical Sciences & 0 & 125 & 125 \\
Total of 10 journals & 546 & 2335 & 2881 \\
Total of India & 2202 & 6317 & 8519 \\
Share of 10 journals output in India's total output & 24.80 & 36.96 & 33.82 \\
\hline
\end{tabular}

\section{Highly Cited Papers}

There were 51 highly cited papers in clinical pharmacology (42 papers with citations from 100 to 199, 7 papers with citations from 200 to 299, 1 paper each with citations from 400 to 499 and 600 to 699) together received 8597 citations, leading to average citation per paper of 168.57 . These 51 highly cited papers ( 14 articles, 35 reviews and 1 each conference paper \& letter) had the participation of single organization in 25 papers and participation of more than 2 organizations in 26 papers (16 national collaborative and 13 international collaborative). The 51 highly cited papers involve the participation of 207 authors and 106 organizations.

Among the participation of authors in highly cited 51 papers, 1 paper had the participation of 1 author, 14 papers with 2 and 3 authors each, 8,5 and 5 papers with 4, 5 and 6 authors and 1 paper with 7,8,9 and 25 authors each. The average number of authors per paper was 4.05.

Among the participation of organizations in 51 highly cited papers, 25 papershave the participation of 1 organization, 16 papers with 2 organizations, 6 papers with 3 organizations, 2 papers with 4 organizations, 1 paper with 5 organizations and 1 paper with 22 organizations. The average number of organizations per paper was 2.08 .

Among the 106 participating organizations in 51 highly cited papers, 59 were Indian. Of the Indian organizations, the largest number of papers (4) were contributed by National Institute of Pharmaceutical Education \& Research (NIPER), Mohali, followed by 2 papers each by All India Institute of Medical Sciences, New Delhi, National Institute of Mental Health \& Neurosciences, Bangalore, Institute of Life Sciences, Bhubaneswar, Jadavpur University, Kolkata, Jamia Hamdard University, Delhi, Sathybama University and Matrix Lab Ltd, Medak, Andhra Pradesh and 1 paper each by 51 other Indian organizations.

Among 59 Indian participating organizations, 20 were universities, 12 research institutes. 9 pharmacy colleges, 5 medical colleges, 4 each institutes of national importance and industrial enterprises, 2 each as engineering colleges and general colleges and 1 hospital.

These 51 high cited papers were published in 33 journals, including 9 papers in Nanomedicine, 3 each in Bioorganic \& Medicinal Chemistry, Drug Discovery Today and Journal of Antimicrobial Therapy, 2 papers each in Current Drug Delivery and Pharmaceutical Research, and 1 paper each in 28 other journals, namely Acta Pharmaceutica, Alimentary Phar- macology \& Therapy, Advanced Drug Delivery Review, Basic \& Clinical Pharmacology \& Toxicology, Biochemical Pharmacology, Current Drug Metabolism, Current Opinion in Pharmacology, Current Medicinal Chemistry, Current Medicinal Chemistry-Anticancer Agents, ChemBioChem, Chinese Medicine, Chirality Review, Current Drug Metabolism, European Journal of Medicinal Chemistry, Journal of Control Release, European Neuropsypharmacology, Life Sciences, International Journal of Review of Pharmacology, Journal of Drug Targeting, .Journal of Occupational Health, Marine Drugs, International Journal of Pharmaceutics, International Journal of Pharmaceuticology, Neuropsychopharmacology, Pharmacological Reports, Toxicological Sciences and Vascular Pharmacology.

\section{SUMMARY \& CONCLUSION}

In clinical pharmacology, 177465 and 8519 publications were published by World and India during 2005-14. The world publications increased from 15680 to 20332 and India's publications from 284 to 1565 from the year 2005 to year 2014, registering annual average growth rates of 3.01\% and $25.89 \%$. India's global publication share in clinical pharmacology was 4.80 , which increased from $2.65 \%$ to $6.69 \%$ from $2005-09$ to $2010-14$. India's publications in clinical pharmacology registered the average citation per publication of 6.75 during 2005-14, which decreased from 14.38to 4.08 from 2005-09 to 2010-14. The global research output in clinical pharmacology originated in more than 100 countries during 2005-14, with highest publication share (32.70\%) coming from USA, followed by U.K. (8.74\% share), China (7.37\%), Germany (6.28\%), Italy (5.79\%), Japan $(4.82 \%)$, India (4.04\%), Spain (3.88\%), France $(3.70 \%)$ and Canada (3.64\%) during 2005-14. The global publication share has increased in China, India, Italy and France, as against decrease in USA, Germany, U.K., Canada, Spain and Japan from 2005-09 to 2010-14. Around $61 \%$ of the Indian publications onclinical pharmacology registered citations from 100 to 605 citations and showed highly skewed distribution. On one hand 44.59\% (3799) publications accounted for 1 to 10 citations per paper ( $23.277 \%$ citation share) as against $0.58 \%$ (49) publications accounted for more than 7978 citations (13.88\% citation share). India's clinical pharmacology output registered international collaborative publications share of $12.22 \%$, decreasing from $13.99 \%$ to $11.76 \%$ from $2005-09$ to $2010-14$. Among international collaborative output, USA registered the highest share (43.52\%), followed by UK (12.10\%), Australia (6.44\%), Canada (6.24\%), Malaysia (6.15\%), 
Saudi Arabia (5.96\%), Belgium (5.86\%), Germany (5.67\%), Switzerland (5.48\%) and South Korea (5.84\%) during 2005-14. The top 15 most productive Indian organizations together contributed $19.25 \%$ and $29.06 \%$ share of the cumulative publications and citations output of India in clinical pharmacology during 2005-14. The average productivity per organization, citation per paper, h-index and share of international collaborative papers of these top 15 organizations were 109.33. 10.18, 16.8 and $11.13 \%$ during $2005-14$. The top 15 most productive Indian authors together contributed $4.71 \%$ and $8.39 \%$ share of the cumulative publications and citations output of India in clinical pharmacology during 2005-14. The average productivity per author, citation per paper, h-index and share of international collaborative papers of these top 15 authors were 26.73. 12.03, 9.47 and $15.71 \%$ during 2005-14. The 10 most productive journals in India's clinical pharmacology research together contributed $33.82 \%$ share to the total India's publication output in clinical pharmacology during 2005-14. India's publication output in clinical pharmacology had on 51 highly cited papers (receiving 100 or more citations) and together received 8597 citations, leading to average citation per paper of 168.57 . These 51 highly cited papers ( 14 articles, 35 reviews and 1 each conference paper \& letter) had the participation of single organization in 25 papers and participation of more than 2 organizations in 26 papers (16 national collaborative and 13 international collaborative). The 51 highly cited papers involve the participation of 207 authors and 106 organizations. These 51 high cited papers were published in 33 journals, including 9 papers in Nanomedicine, 3 each in Bioorganic o Medicinal Chemistry, Drug Discovery Today and Journal of Antimicrobial Therapy 93 papers each), etc.

\section{ABOUT AUTHORS}

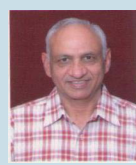

Dr B.M.Gupta: Is now a retired scientist. He was working as Emeritus Scientist in the National Institute of Science, Technology \& Development Studies (NISTADS), CSIR, New Delhi from 2008 to 2013. B.M.Gupta retired from CSIR as Scientist G in July 2008. Dr B.M.Gupta has completed B.Lib Sci from Kurukshetra University in 1971. Associatship in Documentation from INSDOC in 1975 and PhD from Karnatak University in 1999. Mr Gupta is the recipient of the Fullbright Professional Fellowship in Library \& Information Science (1999) and is elected the Fellow of the Society for Information Science (2007). Dr Gupta has more than 200 research papers mainly in the area of scientometricst, which are published in learned national and international journals.

Ritu Gupta: Had completed his B.Lib. Sci. and M.Lib Sci degrees from Annamalai University and at present registered for Ph.D degree in the Department of Library \& Information Science at Sri Venkateswara University, Tirupathi, Andhra Pradesh. She has published more than 45 papers in the area of bibliometrics and scientometrics.

\section{REFERENCES}

1. Clinical pharmacology. 18 April 2016. https://en.wikipedia.org/wiki/Clinical_pharmacology

2. What is Clinical Pharmacology? 2016. http://www.ascpt.org/Knowledge-Center/ What-is-Clinical-Pharmacology.

3. Buclin T, Gotta V, Fuchs A, Widmer N and Aronson J. An agenda for UK clinical pharmacology: Monitoring drug therapy. British Journal of Clinical Pharmacology. 2012;73(6):917-23

4. Birkett D, Brøsen K, Cascorbi I, Gustafsson LL, Maxwell S, Rago L, et al. Clinical Pharmacology in Research, Teaching and Health Care. Considerations by IUPHAR, the International Union of Basic and Clinical Pharmacology. Basic Clinical Pharmacolology \& Toxicology. 2010;107(1):531-59.

5. Dollery CT. Clinical pharmacology-the first 75 years and a view of the future. British Journal of Clinical Pharmacology. 2006;61(6):650-65.

6. Kshirsagar NA. History of clinical pharmacology in India: A brief account. In: Patil PN, Gulati OD, Balaraman R, editors. Topics in the history of pharmacology. $1^{\text {st }}$ ed. Ahmadabad India: RK Goyal Publisher; 2005. pp. 148-69.

7. Govt. of India, New Delhi: Annual report 2010-2011; 2011. Ministry of Chemicals and Fertilizers. Available from: http://www.pharmaceuticals.gov.in [Last accessed on 2012 May].
8. Jayasheel, B. G. Recent changes in regulations related to clinical trials approval in India. Pharma Times. 2012;44(05):45.

9. Cll-Pharma-Summit-Report-India Pharma Inc.: Capitalising on India's Growth Potential. London: PricewaterhouseCoopers (PWC): 2010. [Last accessed on 2012 Nov].PricewaterhouseCoopers 2010. Available from: http://www.pwc. com/in/en/assets/pdfs/pharma/PwC-CII-pharma-Summit-Report-22Nov.pdf

10. Benyamina A, Blecha L, Reynaud M. Translational research and experimental medicine in 2012. Lancet. 2012;379(9810):1.

11. Nilima A. Kshirsagar, Sagar S. Bachhav, Laxmikant A. Kulkarni, and Vijaykumar. Clinical pharmacology training in India: Status and need. Indian Journal of Phar macolology. 2013;45(5):429-33.

12. Mueen Ahmed, K.K., Gupta, Ritu and Gupta, B.M. Pharmocology research in India: A scientometric analysis of publications output, 2003-12. Indian Journal of Pharmaceutical Education and Research. 2014;48(2):16-34.

13. Gupta R, Mueen Ahmed K.K. and Gupta BM. High productivity pharmaceutical organizations in India: A study of their performance during 2008-12 Journal of Young Pharmacists. 2014;6(2):4-13.

14. Nayak, Yogendra, Mor, Vijay and Unnikrishnan, M. K. Research in pharmacy schools of India: A study based on Scopus database. Indian Journal of Pharmaceutical Education \& Research 2011. 45(1):7. 
Ahmed et al.: Clinical Pharmacology Publications Output

\begin{tabular}{|c|c|c|c|c|c|}
\hline Articles & 6426 & 75.43 & Journals & 8488 & 99.64 \\
\hline Reviews & 1607 & 18.86 & Trade publications & 15 & 0.18 \\
\hline Letters & 244 & 2.86 & Books & 11 & 0.13 \\
\hline Editorials & 68 & 0.80 & Book series & 4 & 0.05 \\
\hline Conference papers & 60 & 0.70 & Conference proceedings & 1 & 0.01 \\
\hline Short surveys & 55 & 0.65 & & 8519 & 100.00 \\
\hline Notes & 35 & 0.41 & & & \\
\hline Book chapters & 11 & 0.13 & & & \\
\hline Articles in press & 11 & 0.13 & & & \\
\hline \multirow[t]{2}{*}{ Erratum } & 2 & 0.02 & & & \\
\hline & 8519 & 100.00 & & & \\
\hline
\end{tabular}

List of organization type published in Clinical Pharmacology Research in India during 2005-14

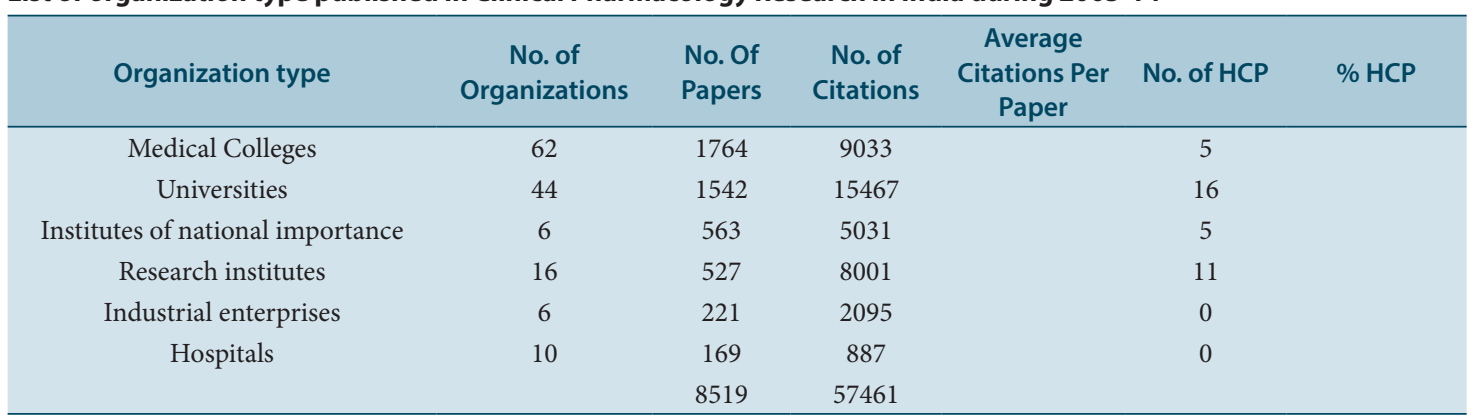

\section{APPENDIX 1.}

\section{List of Top 15 Highly Cited Papers in Clinical Pharmacology in India, 2005-14}

1. Maheshwari, R.K., Singh, A.K., Gaddipati, J., Srimal, R.C.Multiple biological activities of curcumin: A short review (Conference Paper). Life Sciences 2006, 78 (18), 2081-2087. Cited 605 times.

2. Rahman, I., Biswas, S.K., Kirkham, P.A.Regulation of inflammation and redox signaling by dietary polyphenols (Article). Biochemical Pharmacology 2006 72 (11), pp. 1439-1452. Cited 495 times.

3. Sudhakar,Y., Kuotsu, K., Bandyopadhyay, A.K.Buccalbioadhesive drug delivery A promising option for orally less efficient drugs (Review). (2006) Journal of Controlled Release 2006, 114 (1), 15-40. Cited 283 times.

4. Thakkar, K.N., Mhatre, S.S., Parikh, R.Y.Biological synthesis of metallic nanoparticles (Review). Nanomedicine: Nanotechnology, Biology, and Medicine 2010, 6 (2), pp. 257-262. Cited 282 times

5. Samad, A., Sultana, Y., Aqil, M.Liposomal drug delivery systems: An update review (Review) Current Drug Delivery 2007, 4 (4), pp. 297-305. Cited 280 times.

6. Parveen, S., Misra, R., Sahoo, S.K.Nanoparticles: A boon to drug delivery therapeutics, diagnostics and imaging (Review). Nanomedicine: Nanotechnology, Biology, and Medicine 2012, 8 (2), pp. 147-166. Cited 277 times.

7. Kedar, U., Phutane, P., Shidhaye, S., Kadam, V.Advances in polymeric micelles for drug delivery and tumor targeting (Review). Nanomedicine: Nanotechnology, Biology, and Medicine 2010, 6 (6), pp. 714-729. Cited 222 times.

8. Tseng, Y.-C., Mozumdar, S., Huang, L.Lipid-based systemic delivery of siRNA (Review). Advanced Drug Delivery Reviews 2009, 61 (9), pp. 721-731. Cited 215 times.

9. Birari, R.B., Bhutani, K.K.Pancreatic lipase inhibitors from natural sources: unexplored potential (Review). Drug Discovery Today 2007, 12 (19-20), pp. 879889. Cited 205 times

10. Fayaz, A.M., Balaji, K., Girilal, M., Yadav, R., Kalaichelvan, P.T., Venketesan, R. Biogenic synthesis of silver nanoparticles and their synergistic effect with antibiotics: a study against gram-positive and gram-negative bacteria (Article). Nanomedicine: Nanotechnology, Biology, and Medicine 2010, 6 (1), pp. e103-e109. Cited 197 times.

11. Mishra, B., Patel, B.B., Tiwari, S.Colloidal nanocarriers: a review on formulation technology, types and applications toward targeted drug delivery (Review). Nanomedicine: Nanotechnology, Biology, and Medicine 2010, 6 (1), pp. e9-e24. Cited 184 times.

12 Pandya, N.M., Dhalla, N.S., Santani, D.D.Angiogenesis-a new target for future therapy (Review). Vascular Pharmacology 2006, 44 (5), pp. 265-274. Cited 180 times.
13 Srivastava, V., Negi, A.S., Kumar, J.K., Gupta, M.M., Khanuja, S.P.S.Plant-based anticancer molecules: A chemical and biological profile of some important leads (Review). Bioorganic and Medicinal Chemistry 2005, 13 (21), pp. 58925908. Cited 180 times.

14. Jain, K., Kesharwani, P., Gupta, U., Jain, N.K.Dendrimer toxicity: Let's meet the challenge (review). International Journal of Pharmaceutics 2010, 394 (1-2), pp. 122-142. Cited 169 times.

15. Khanna, D., Sethi, G., Ahn, K.S., Pandey, M.K., Kunnumakkara, A.B., Sung, B. Aggarwal, A., Aggarwal, B.B.Natural products as a gold mine for arthritis treatment (Review). Current Opinion in Pharmacology 2007. 7 (3), pp. 344-351. Cited 169 times.

- Karmali, P.P. Chaudhuri, A. Cationic liposomes as non-viral carriers of gene medicines: Resolved issues, open questions, and future promises (2007) Medicinal Research Reviews, 27 (5), pp. 696-722. Cited 167 times. DOI: $10.1002 / \mathrm{med} .20090$

Document Type: Review

Source: Scopus

- Premanathan, M., Karthikeyan, K., Jeyasubramanian, K., Manivannan, G. Selective toxicity of $\mathrm{ZnO}$ nanoparticles toward Gram-positive bacteria and cancer cells by apoptosis through lipid peroxidation (2011) Nanomedicine: Nanotechnology, Biology, and Medicine, 7 (2), pp. 184-192. Cited 166 times. DOI: 10.1016/j.nano.2010.10.001

Document Type: Article

Source: Scopus

- Kamalakkannan, N., Prince, P.S.M. Antihyperglycaemic and antioxidant effect of rutin, a polyphenolic flavonoid, in streptozotocin-induced diabetic wistar rats (2006) Basic and Clinical Pharmacology and Toxicology, 98 (1) pp. 97-103. Cited 163 times.

DOI: $10.1111 /$ j.1742-7843.2006.pto_241.x

Document Type: Article

Source: Scopus

- Mishra, B.B., Tiwari, V.K. Natural products: An evolving role in future drug discovery (2011) European Journal of Medicinal Chemistry, 46 (10), pp. 47694807. Cited 156 times.

DOI: 10.1016/j.ejmech.2011.07.057

Document Type: Review

Source: Scopus

- Nanda, A., Saravanan, M. Biosynthesis of silver nanoparticles from Staphylococcus aureus and its antimicrobial activity against MRSA and MRSE (2009) Nanomedicine: Nanotechnology, Biology, and Medicine, 5 (4), pp. 452-456. Cited 155 times.

DOI: 10.1016/j.nano.2009.01.012

Document Type: Article

Source: Scopus 